Article

\title{
Environmentally Stable Chiral-Nematic Liquid-Crystal Elastomers with Mechano-Optical Properties
}

\author{
Kyosun Ku $^{1}$, Kyohei Hisano ${ }^{1}{ }^{D}$, Seiya Kimura ${ }^{1}$, Tomoki Shigeyama ${ }^{1}$, Norihisa Akamatsu ${ }^{2}$, Atsushi Shishido ${ }^{2}$ \\ and Osamu Tsutsumi $1, *$ (D) \\ 1 Department of Applied Chemistry, Ritsumeikan University, 1-1-1 Nojihigashi, Kusatsu 525-8577, Japan; \\ gr0343xf@ed.ritsumei.ac.jp (K.K.); hisano@fc.ritsumei.ac.jp (K.H.); sc0040pf@gmail.com (S.K.); \\ sc0060kf@ed.ritsumei.ac.jp (T.S.) \\ 2 Laboratory for Chemistry and Life Science, Tokyo Institute of Technology, 4259 Nagatsuta, Midori-ku, \\ Yokohama 226-8503, Japan; akamatsu@res.titech.ac.jp (N.A.); ashishid@res.titech.ac.jp (A.S.) \\ * Correspondence: tsutsumi@sk.ritsumei.ac.jp; Tel.: +81-77-561-5966
}

check for updates

Citation: Ku, K.; Hisano, K.; Kimura, S.; Shigeyama, T.; Akamatsu, N.; Shishido, A.; Tsutsumi, O.

Environmentally Stable ChiralNematic Liquid-Crystal Elastomers with Mechano-Optical Properties. Appl. Sci. 2021, 11, 5037. https:// doi.org/10.3390/app11115037

Academic Editor: Mohamed Amine Gharbi

Received: 28 April 2021

Accepted: 26 May 2021

Published: 29 May 2021

Publisher's Note: MDPI stays neutral with regard to jurisdictional claims in published maps and institutional affiliations.

Copyright: (c) 2021 by the authors. Licensee MDPI, Basel, Switzerland. This article is an open access article distributed under the terms and conditions of the Creative Commons Attribution (CC BY) license (https:// creativecommons.org/licenses/by/ $4.0 /)$.

\begin{abstract}
Chiral-nematic liquid crystal ( $\left.\mathrm{N}^{*} \mathrm{LC}\right)$ elastomers exhibit mechano-optical responsive behavior. However, practical sensor applications have been limited by the intrinsic sensitivity of $\mathrm{N}^{*}$ LC elastomers to environmental conditions, such as temperature. Although densely cross-linked LC network polymers exhibit high thermal stability, they are not proper for the mechanical sensor due to high glass transition temperatures and low flexibility. To overcome these issues, we focused on enhancing thermal stability by introducing noncovalent cross-linking sites via intermolecular interactions between LC molecules bonded to the polymer network. $\mathrm{N}^{*}$ LC elastomers with a cyanobiphenyl derivative as a side-chain mesogen exhibited mechano-optical responsive behavior, with a hypsochromic shift of the reflection peak wavelength under an applied tensile strain and quick shape and color recovery owing to high elasticity. Notably, the $\mathrm{N}^{*} \mathrm{LC}$ elastomers showed high resistance to harsh environments, including high temperatures and various solvents. Interactions, such as $\pi-\pi$ stacking and dipole-dipole interactions, between the cyanobiphenyl units can act as weak cross-links, thus improving the thermal stability of the LC phase without affecting the mechanooptical response. Thus, these $\mathrm{N}^{*} \mathrm{LC}$ elastomers have great potential for the realization of practical mechano-optical sensors.
\end{abstract}

Keywords: chiral-nematic liquid crystal elastomer; mechanochromism; selective reflection; noncovalent cross-linking; thermal stability

\section{Introduction}

Stimuli-responsive photonic materials have attracted great interest owing to their tunable optical behavior, which is useful for applications in areas such as flexible electronics and soft robotics [1-3]. In particular, mechano-optical responsive materials change their optical properties under the application of physical stimuli, such as grinding, pressure, and tensile or shear strain [4-9]. Liquid-crystal (LC) elastomers are promising advanced materials in which the orientation of the mesogens is strongly coupled to the polymer network; thus, electro-, mechano-, or thermo-responsive effects on the macroscopic shape and the microscopic molecular orientation can be observed simultaneously [10-18]. Notably, chiralnematic $\left(\mathrm{N}^{*}\right)$ LC elastomers have unique optical properties based on the helical structure of the $\mathrm{N}^{*}$ LC system [19-21]. $\mathrm{N}^{*}$ LC elastomers spontaneously form a helically twisted molecular orientation, with the orientational direction of the mesogens rotating along the helical axis [22-24]. Thus, $\mathrm{N}^{*} \mathrm{LC}$ elastomers exhibit Bragg reflection and selectively reflect circularly polarized light of a particular wavelength. The reflection wavelength, $\lambda$, depends on the helical pitch, $P$, of the $\mathrm{N}^{*}$ LC elastomers, as expressed by the following equation:

$$
\lambda=n_{\mathrm{ave}} \cdot P,
$$


where $n_{\text {ave }}$ is the average of the ordinary and extraordinary refractive indices of the LCs [25-28]. In 2001, Finkelmann et al. reported a dye-doped $\mathrm{N}^{*}$ LC elastomer that acted as a mechanically tunable laser [29]. In this system, a mechanical stimulus applied to the elastomer changed the macroscopic shape in accordance with the change in the helical orientation. This pioneering work provided a basis for the development of $\mathrm{N}^{*} \mathrm{LC}$ elastomers as stimuli-responsive photonic materials [30-34]. The helical orientation of an $\mathrm{N}^{*} \mathrm{LC}$ elastomer is very sensitive to various external stimuli, such as heat [31], light [32], electric fields [33], and humidity [34]. For the development of mechano-sensing applications, a high sensitivity to multiple stimuli is unfavorable because the external stimuli can interfere with the observation of a pure mechano-optical response. Thus, stability in various environments, except under mechanical stimuli, is highly desirable for the development of $\mathrm{N}^{*}$ LC elastomers with highly sensitive mechano-optical response behavior.

In recent decades, $\mathrm{N}^{*} \mathrm{LC}$ network polymers with high cross-linking densities have attracted practical interest because of their thermally stable optical properties [35-37]. However, dense cross-linking is not appropriate for mechano-optical sensors because of the associated high glass transition temperature and low flexibility [38,39]. Moreover, the cross-linker acts as an impurity that destabilizes the LC phase, leading to a decrease in the isotropic phase transition temperature [40]. Therefore, to utilize an $\mathrm{N}^{*} \mathrm{LC}$ elastomer for mechano-optical applications, high thermal stability with a low cross-linking density is necessary. Herein, we report a useful design method for thermally stable $\mathrm{N}^{*} \mathrm{LC}$ networked polymers with low densities of cross-linking sites. Our strategy for enhancing the thermal stability of network polymers involves introducing noncovalent interactions between the mesogenic moieties in the side chains of network polymers. In this study, we employed a cyanobiphenyl derivative as a side-chain mesogen because intermolecular interactions such as $\pi-\pi$ stacking and dipole-dipole interactions between cyanobiphenyl mesogens are wellknown to impart polymeric materials with high resistance to thermal treatment [41-44]. We hypothesized that these interactions between mesogens could act as weak cross-links and thus improve the thermal stability of the LC phase without disturbing the mechanical and optical behavior. The synthesized $\mathrm{N}^{*} \mathrm{LC}$ elastomers with noncovalent cross-linking sites showed good thermal stability and maintained their mechano-optical response behavior under harsh environmental conditions.

\section{Materials and Methods}

\subsection{Materials}

The chemical structures of the materials used to prepare the $\mathrm{N}^{*} \mathrm{LC}$ elastomers are shown in Scheme 1. The base LC monomers (HAB and CN) were obtained from a commercial supplier and used after recrystallization from methanol. The plasticizer (5CB), cross-linker (HDDA), and photoinitiator (Irgacure 651) were purchased from commercial suppliers and used as received. A chiral monomer (ISBCD) was synthesized and purified as reported previously (Scheme S1, Text S1, and Figures S1-S3) [45,46].

\subsection{Preparation of $N^{*} L C(x)$ Elastomers}

$\mathrm{N}^{*} \mathrm{LC}(x)$ elastomers, where $x$ denotes the molar ratio of ISBCD in the monomer mixture, were prepared by photopolymerization. A schematic of the preparation method is shown in Figure 1, and details are given in Text S2-S4. Monomer mixtures were prepared (Table 1) [47] and then injected into a homemade glass cell at the isotropic temperature $\left(80^{\circ} \mathrm{C}\right)$. In the cell, $110-\mu \mathrm{m}$-thick PDMS films were placed on the glass substrate to aid in removing the prepared elastomers. The monomer mixture in the cell was then cooled to the LC temperature $\left(25^{\circ} \mathrm{C}\right)$ and photopolymerized by irradiation with UV light at $365 \mathrm{~nm}$ $\left(5.0 \mathrm{~mW} \mathrm{~cm}^{-2}\right)$ for $5 \mathrm{~min}$ in the $\mathrm{N}^{*} \mathrm{LC}$ phase. The resultant $\mathrm{N}^{*} \mathrm{LC}(x)$ elastomer film was peeled off the PDMS layer. The thickness of the obtained $\mathrm{N}^{*}$ LC elastomer film was $55 \mu \mathrm{m}$. All the resultant films showed bright selective reflection. 
<smiles>C=CC(=O)OCCCCCCOc1ccc(C(=O)Oc2ccc(OC)cc2)cc1</smiles>

HAB<smiles>C=CC(=O)OCCCCCCOc1ccc(-c2ccc(C#N)cc2)cc1</smiles>

$\mathrm{CN}$<smiles>C=CC(=O)OCCCCCCOC(=O)C=C</smiles>

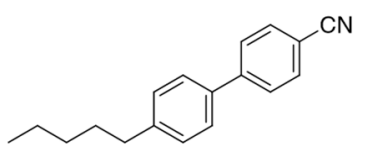

$5 \mathrm{CB}$

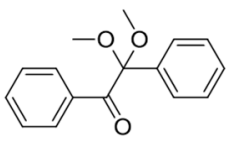

Irgacure 651

Scheme 1. Chemical structures of the LC monomers (HAB and CN), chiral monomer (ISBCD), cross-linker (HDDA), plasticizer (5CB), and photoinitiator (Irgacure 651) used to synthesize $\mathrm{N}^{*} \mathrm{LC}(x)$ elastomers.

Table 1. Monomer mixtures for synthesizing $\mathrm{N}^{*} \mathrm{LC}(x)$ elastomers.

\begin{tabular}{|c|c|c|c|c|c|c|}
\hline $\mathbf{x}$ & $\begin{array}{c}\text { HAB } \\
(\mathrm{mol} \%)\end{array}$ & $\begin{array}{c}\mathrm{CN} \\
(\mathrm{mol} \%)\end{array}$ & $\begin{array}{c}5 \mathrm{CB} \\
(\mathrm{mol} \%)\end{array}$ & $\begin{array}{l}\text { Irgacure } 651 \\
(\mathrm{~mol} \%)\end{array}$ & $\begin{array}{l}\text { HDDA } \\
\text { (mol\%) }\end{array}$ & $\begin{array}{l}\text { ISBCD } \\
(\mathrm{mol} \%)\end{array}$ \\
\hline 2.0 & \multirow{6}{*}{40} & \multirow{6}{*}{40} & \multirow{6}{*}{20} & \multirow{6}{*}{1} & \multirow{6}{*}{7} & 2.0 \\
\hline 2.2 & & & & & & 2.2 \\
\hline 2.4 & & & & & & 2.4 \\
\hline 2.6 & & & & & & 2.6 \\
\hline 2.8 & & & & & & 2.8 \\
\hline 3.0 & & & & & & 3.0 \\
\hline
\end{tabular}

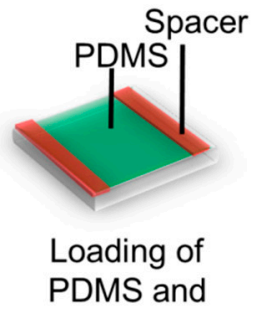

PDMS and

spacer
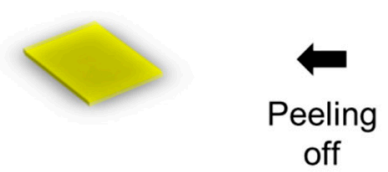

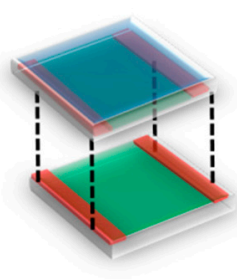

365-nm UV light

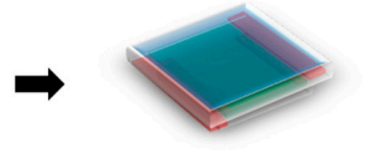

Penetration of mixture

\section{Photo} polymerization

Figure 1. Schematic illustration of the fabrication method for $\mathrm{N}^{*} \mathrm{LC}(x)$ elastomer films.

\subsection{Characterization of $N^{*} L C(x)$ Elastomers}

The thermodynamic properties of the $\mathrm{N}^{*} \mathrm{LC}(x)$ elastomers were determined by differential scanning calorimetry (DSC, X-DSC7000, SEIKO Instruments, $10{ }^{\circ} \mathrm{C} \mathrm{min}^{-1}$ ). The phase sequences and phase transition behavior were determined by polarized optical microscopy (POM, Olympus, EX51TH) using a hot stage (Instec, HCS302 hot stage and $\mathrm{mK} 1000$ controller). To evaluate the mechano-optical responsive behavior, the reflectance 
spectra of the elastomers were recorded using a UV-visible diode-array spectrometer (StellarNet BLUE-Wave spectroscope) under static tensile strain. Stress-strain curves were measured using a tensile tester (Instron 5943, Instron) at room temperature with a strain rate of $2 \mathrm{~mm} \mathrm{~min}^{-1}$. The Young's modulus of each elastomer film was determined in the tensile deformation range of $0.25-1.0 \%$. Films with dimensions of $20 \mathrm{~mm} \times 5 \mathrm{~mm}$ were used for the tensile tests.

\section{Results and Discussion}

\subsection{Phase Transition Behavior}

The phase transition behavior of the $\mathrm{N}^{*} \mathrm{LC}(x)$ elastomer films was investigated using POM (Figure S4) and DSC (Figures S5-S7). In the monomer mixture for $\mathrm{N}^{*} \mathrm{LC}(2.0)$, the isotropic-to-LC phase transition was observed at $28{ }^{\circ} \mathrm{C}$ during the cooling process. From the planar texture shown in the POM images (Figure S4), we concluded that the LC phase observed in the monomer mixture was an $\mathrm{N}^{*} \mathrm{LC}$ phase. After polymerization, the $\mathrm{N}^{*} \mathrm{LC}$ phase observed in the monomeric state was fixed in the resultant elastomers. As summarized in Table 2, the LC temperature ranges of the elastomers with different ISBCD concentrations were similar, with an $\mathrm{N}^{*} \mathrm{LC}$ phase observed from $\sim 10$ to $90{ }^{\circ} \mathrm{C}$. These results indicate that the LC behavior of the elastomers was not affected by the chiral dopant concentration. ISBCD has been reported to have a very large helical twisting power $\left(\mathrm{HTP}=43 \mu \mathrm{m}^{-1} \mathrm{~mol}^{-1}\right)$ [46]; therefore, only a small amount of ISBCD was necessary to induce a helical LC alignment. Because only a low concentration of chiral dopant was used, the thermodynamic properties of the elastomers were not affected.

Table 2. Phase transition temperatures of $\mathrm{N}^{*} \mathrm{LC}(x)$ monomer mixtures and elastomers with different ISBCD contents.

\begin{tabular}{ccc}
\hline $\mathbf{x}$ & \multicolumn{2}{c}{${\text { Phase Transition Temperature }\left({ }^{\circ} \mathbf{C}\right)}$} \\
\cline { 2 - 3 } & Monomer Mixture $^{\mathbf{1}}$ & Elastomer $^{\mathbf{1}}$ \\
\hline 2.0 & $\mathrm{~N}^{*} 28 \mathrm{I}$ & $\mathrm{G} 9 \mathrm{~N}^{*} 93 \mathrm{I}$ \\
2.2 & $\mathrm{~N}^{*} 28 \mathrm{I}$ & $\mathrm{G} 12 \mathrm{~N}^{*} 90 \mathrm{I}$ \\
2.4 & $\mathrm{~N}^{*} 27 \mathrm{I}$ & $\mathrm{G} 11 \mathrm{~N}^{*} 90 \mathrm{I}$ \\
2.6 & $\mathrm{~N}^{*} 27 \mathrm{I}$ & $\mathrm{G} 8 \mathrm{~N}^{*} 91 \mathrm{I}$ \\
2.8 & $\mathrm{~N}^{*} 27 \mathrm{I}$ & $\mathrm{G} 12 \mathrm{~N}^{*} 95 \mathrm{I}$ \\
3.0 & $\mathrm{~N}^{*} 26 \mathrm{I}$ & $\mathrm{G} 10 \mathrm{~N}^{*} 92 \mathrm{I}$ \\
\hline
\end{tabular}

${ }^{1}$ Abbreviations: $\mathrm{G}$, glassy; $\mathrm{N}^{*}$, chiral nematic; I, isotropic. The phase transition temperatures were determined by POM for the monomer mixtures and DSC for the elastomers.

The $\mathrm{N}^{*} \mathrm{LC}$ phase of the elastomers was enantiotropic, indicating that the LC phase was reversibly formed during both the heating and cooling processes (Figure 2a). When the $\mathrm{N}^{*} \mathrm{LC}(x)$ elastomers were cooled from the isotropic phase, the $\mathrm{N}^{*} \mathrm{LC}$ phase exhibited the same optical texture immediately below the isotropic- $\mathrm{N}^{*} \mathrm{LC}$ phase transition temperature. Generally, polymer LCs tend to show large supercooling owing to their viscosity. However, in the current system, most of the mesogens were covalently bonded to the polymer main chains through a methylene spacer, and the mesogenic orientation was fixed by crosslinkers. We consider these structural features to be responsible for the high reversibility of the LC behavior and the quick recovery of the LC phase from the isotropic phase $[48,49]$.

To confirm this hypothesis, we prepared a linear LC polymer (l-LCP) without the cross-linking agent using the same polymerization procedure in the LC cell with polyimide alignment layers. As shown in Figure 2b, 1-LCP formed a well-aligned homogeneous $\mathrm{N}^{*} \mathrm{LC}$ phase and exhibited an enantiotropic $\mathrm{N}^{*} \mathrm{LC}$ phase between 0 and $85^{\circ} \mathrm{C}$. As compared to the elastomers, 1-PLC had a lower LC-to-isotropic phase transition temperature. In contrast to the $\mathrm{N}^{*} \mathrm{LC}(x)$ elastomers, which showed complete reversibility of the LC texture, l-LCP became opaque, and a different LC texture was obtained in the $\mathrm{N}^{*} \mathrm{LC}$ phase by cooling from the isotropic phase, as shown in Figure 2b. These observations clearly indicate that 1-PLC formed $\mathrm{N}^{*} \mathrm{LC}$ polydomains after cooling from the isotropic phase and that the order 
parameter of the LC phase was lower than that just after polymerization. Therefore, we concluded that the mesogenic orientation in the $\mathrm{N}^{*} \mathrm{LC}(x)$ elastomers is stabilized and memorized by cross-linking.

(a)

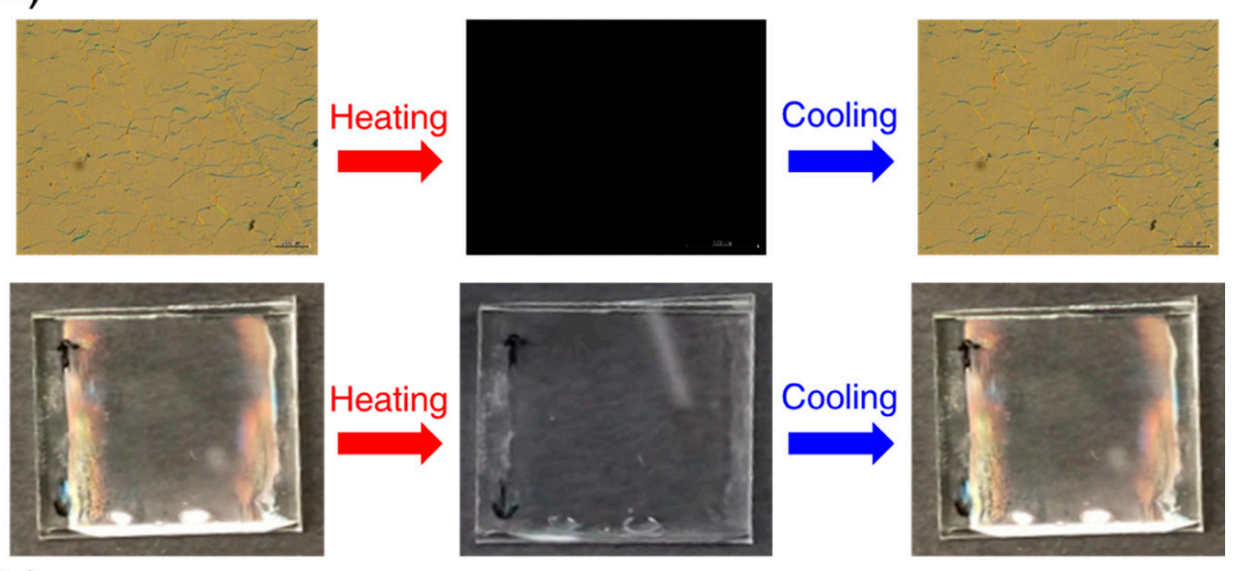

(b)
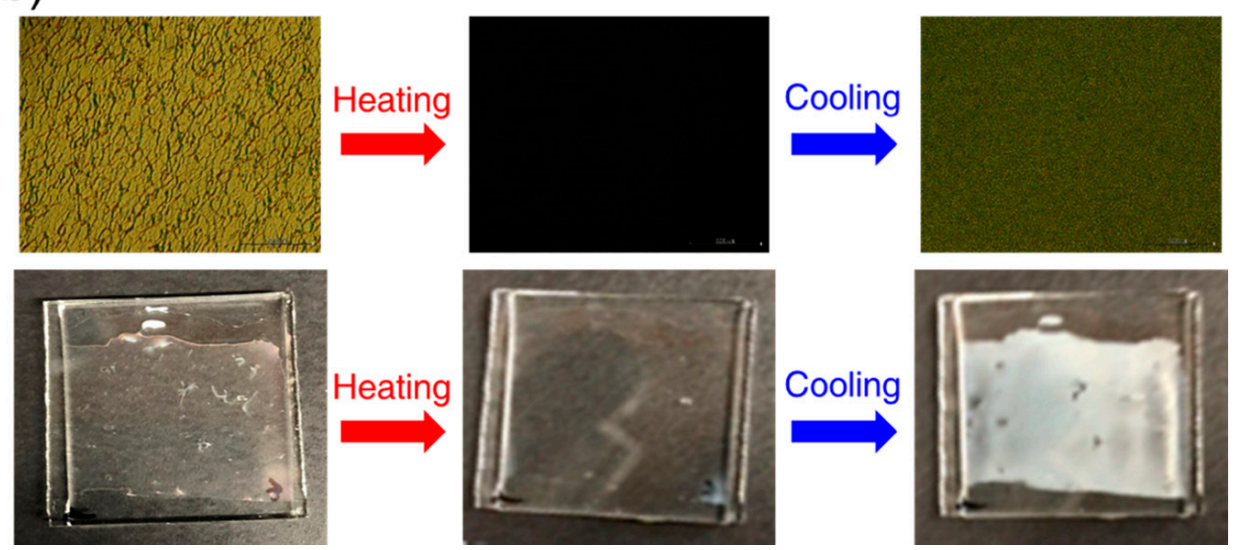

Figure 2. Phase transition behaviors during heating and cooling processes: (a) $\mathrm{N}^{*} \mathrm{LC}(2.0)$ elastomer and (b) 1-LCP.

Next, to investigate the effects of the concentration of the $\mathrm{CN}$ monomer on the thermodynamic behavior, we synthesized $\mathrm{N}^{*} \mathrm{LC}(2.0)$ elastomers with different LC monomer ratios $(\mathrm{HAB} / \mathrm{CN})$. Here, the concentration of ISBCD was fixed at $2.0 \mathrm{~mol} \%$. The molar ratios of the LC monomers and the phase transition temperatures are summarized in Table 3. All the elastomers with different $\mathrm{HAB} / \mathrm{CN}$ ratios exhibited the same glass transition temperature $\left(10^{\circ} \mathrm{C}\right)$. Although the LC-to-isotropic phase transition temperature was not affected by the ISBCD concentration, as discussed above, it showed a dependence on the $\mathrm{HAB} / \mathrm{CN}$ ratio, gradually increasing with an increase in the $\mathrm{CN}$ monomer content. $\mathrm{CN}$ has been reported to form intermolecular interactions [43,44], and we consider intermolecular interactions between $\mathrm{CN}$ units to serve as noncovalent cross-links. As mentioned previously, cross-linking can stabilize the orientation of mesogens in the LC phase. Thus, increasing the $\mathrm{CN}$ content in the elastomer enhanced the thermal stability of the $\mathrm{N}^{*} \mathrm{LC}$ phase. This result supports our working hypothesis that noncovalent cross-linking can be used to improve the thermal stability of the LC phase in the elastomer without increasing the concentration of covalent cross-linkers. 
Table 3. Phase transition temperatures of $\mathrm{N}^{*} \mathrm{LC}(2.0)$ elastomers with different $\mathrm{HAB} / \mathrm{CN}$ ratios.

\begin{tabular}{cc}
\hline Molar Ratio of HAB/CN ${ }^{1}$ & Phase Transition Temperature ${ }^{\mathbf{2}}\left({ }^{\circ} \mathbf{C}\right)$ \\
\hline $70 / 10$ & $\mathrm{G} 10 \mathrm{~N}^{*} 80 \mathrm{I}$ \\
$60 / 20$ & $\mathrm{G} 10 \mathrm{~N}^{*} 83 \mathrm{I}$ \\
$50 / 30$ & $\mathrm{G} 10 \mathrm{~N}^{*} 86 \mathrm{I}$ \\
\hline${ }^{1}$ Contents of other materials in the monomer mixture: $5 \mathrm{CB}, 20 \mathrm{~mol} \%$; HDDA, $7 \mathrm{~mol} \% ;$ ISBCD, 2 mol\%. ${ }^{2}$ Abbrevi-
\end{tabular}
ations: $\mathrm{G}$, glassy; $\mathrm{N}^{*}$, chiral nematic; I, isotropic.

\subsection{Thermal Stability of Optical Properties}

As a representative example, we investigated the thermal stability of the optical properties of the $\mathrm{N}^{*} \mathrm{LC}(2.0)$ elastomers. Generally, the helically twisted molecular orientation of an $\mathrm{N}^{*} \mathrm{LC}$ elastomer is sensitive to temperature $[31,50]$. The twist of the $\mathrm{N}^{*}$ LC helix decreases in the pre-phase transition region upon approaching the phase transition temperature. Therefore, the pitch length increases, and the selective reflection band shifts following thermal treatment. Previous studies have demonstrated that such $\mathrm{N}^{*} \mathrm{LC}$ elastomers can be utilized as thermochromic materials, as the optical properties show a temperature dependence $[50,51]$. However, such temperature responsivity degrades the resolution and accuracy of the mechano-optical response, thus limiting the utility of such $\mathrm{N}^{*}$ LC elastomers for sensing applications. Although densely cross-linked LC polymers typically exhibit excellent thermal stability because both their macroscopic and microscopic structures are fixed, they have high glass transition temperatures and low flexibility. The resultant low flexibility and stretchability make these materials incompatible with mechano-optical sensing applications. In contrast, our proposed $\mathrm{N}^{*} \mathrm{LC}(x)$ elastomers have high flexibility and stretchability owing to their low density of covalent cross-linking but high thermal stability derived from the noncovalent cross-linking sites of the $\mathrm{CN}$ units.

To confirm the effect of the noncovalent cross-linking sites on the thermo-optical stability of the $\mathrm{N}^{*} \mathrm{LC}(2.0)$ elastomers, we investigated the thermo-optical properties of $\mathrm{N}^{*}$ $\mathrm{LC}$ (2.0) elastomers with different $\mathrm{HAB} / \mathrm{CN}$ ratios by measuring the reflectance spectra at various temperatures. The $\mathrm{N}^{*} \mathrm{LC}(2.0)$ elastomer with $\mathrm{HAB} / \mathrm{CN}=40 / 40$ did not exhibit any color change or shift of the reflection peak wavelength with the change in temperature until the isotropic phase transition temperature (Figure 3a,b,e). However, the reflectance intensity decreased spontaneously at the phase transition point (Figure 3d). These results indicate that this $\mathrm{N}^{*} \mathrm{LC}(2.0)$ elastomer has a high thermo-optical stability. In contrast, an $\mathrm{N}^{*} \mathrm{LC}(2.0)$ elastomer with a lower concentration of $\mathrm{CN}$ units $(\mathrm{HAB} / \mathrm{CN}=70 / 10)$ exhibited a hypsochromic shift in the reflection peak wavelength with increasing temperature (Figure $3 \mathrm{c}-\mathrm{e}$ ). These results clearly suggest that the noncovalent cross-linking sites between $\mathrm{CN}$ units in the side chains contribute not only to the thermal stability of the $\mathrm{N}^{*}$ LC phase but also to the thermo-optical stability of the $\mathrm{N}^{*}$ LC elastomer. 
(a)

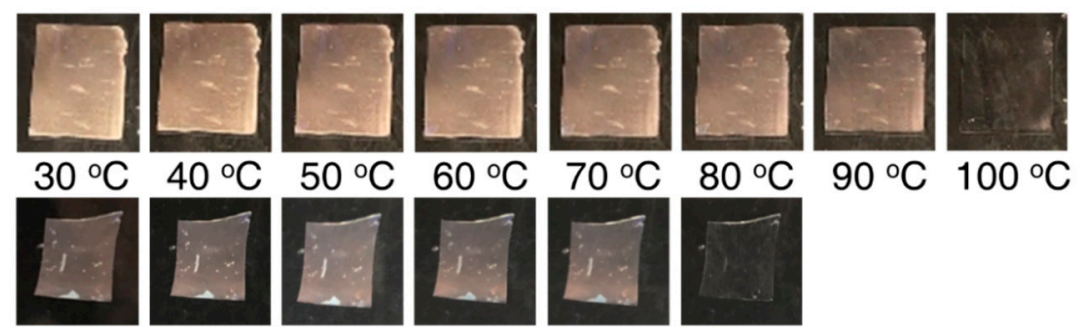

(b)

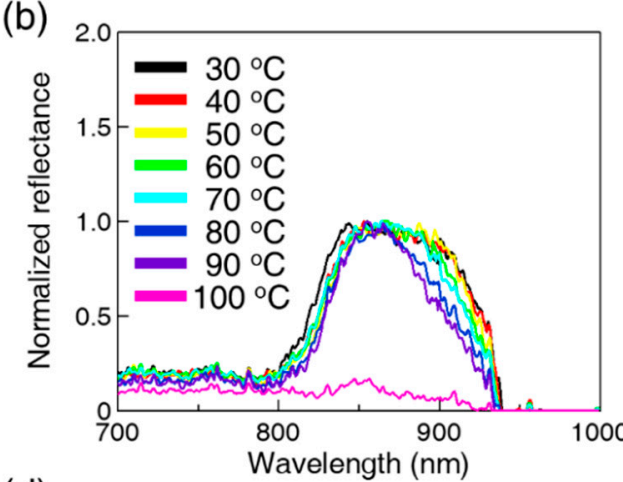

(d)

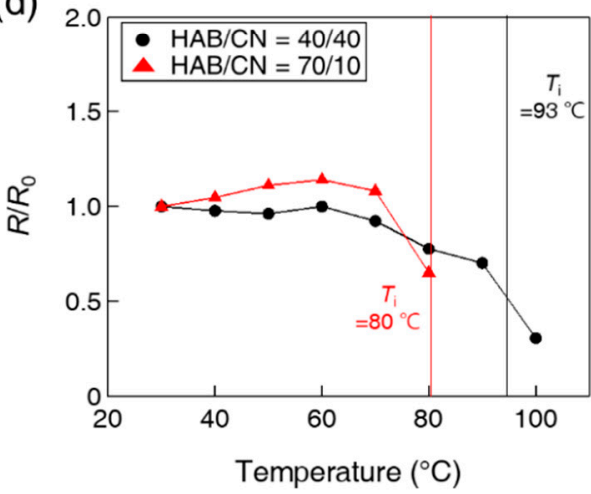

(c)

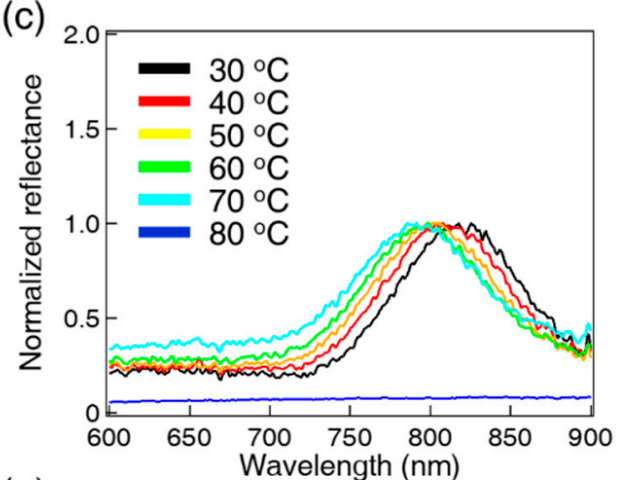

(e)

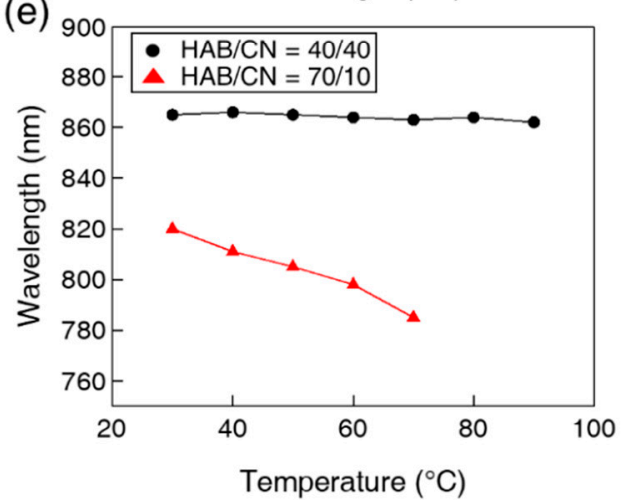

Figure 3. (a) Photographs of $\mathrm{N}^{*} \mathrm{LC}$ (2.0) elastomers with $\mathrm{HAB} / \mathrm{CN}=40 / 40$ (top) and $\mathrm{HAB} / \mathrm{CN}=70 / 10$ (bottom) at different temperatures. Reflectance spectra of $\mathrm{N}^{*} \mathrm{LC}$ (2.0) elastomers with (b) $\mathrm{HAB} / \mathrm{CN}=40 / 40$ and (c) $\mathrm{HAB} / \mathrm{CN}=70 / 10$ at different temperatures. (d) Relative reflectance intensity $\left(R / R_{0} ; R\right.$, reflectance at a certain temperature; $R_{0}$, initial reflectance at $30^{\circ} \mathrm{C}$ ) and (e) reflectance peak wavelength of $\mathrm{N}^{*} \mathrm{LC}(2.0)$ elastomers with $\mathrm{HAB} / \mathrm{CN}=40 / 40$ (black circles and line) and $\mathrm{HAB} / \mathrm{CN}=70 / 10$ (red triangles and line) as a function of temperature.

\subsection{Mechano-Optical Response Behavior and Stability of $N^{*} L C(x)$ Elastomers}

Toward the realization of mechano-optical sensors, we investigated the mechanooptical response behavior of the $\mathrm{N}^{*} \mathrm{LC}(x)$ elastomers under tensile strain. Each of the $\mathrm{N}^{*} \mathrm{LC}(x)$ elastomers showed selective reflection at a particular peak wavelength $(x=2.0$, $835 \mathrm{~nm} ; 2.2,735 \mathrm{~nm} ; 2.4,691 \mathrm{~nm} ; 2.6,635 \mathrm{~nm} ; 2.8,584 \mathrm{~nm}$; and 3.0, $504 \mathrm{~nm}$; Figure 4a). As the concentration of ISBCD units increased, the peak wavelength hypsochromically shifted in accordance with Equation (1). As a representative example, we elongated the $\mathrm{N}^{*} \mathrm{LC}$ (2.0) elastomer (Figure $4 b, c$ ). The film appeared faint red at $0 \%$ strain and changed to an intense orange color at $80 \%$ strain. The color change occurred under elongation, and the initial color was recovered after the removal of the applied strain, and this process could be repeated. The color change was evaluated quantitatively using reflectance measurements. The reflection peak wavelength of the $\mathrm{N}^{*} \mathrm{LC}(2.0)$ elastomer was hypsochromically shifted from the near-IR region $(835 \mathrm{~nm})$ in the initial state to the orange region $(616 \mathrm{~nm})$ at $80 \%$ strain under tensile elongation. The other $\mathrm{N}^{*} \mathrm{LC}(x)$ elastomers also exhibited similar mechano-optical response behavior, with the reflection peak wavelengths hypsochromically shifted under elongation (Figure S8). 
(a)

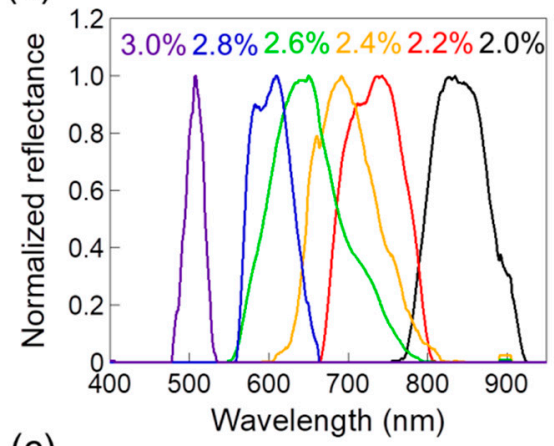

(c)

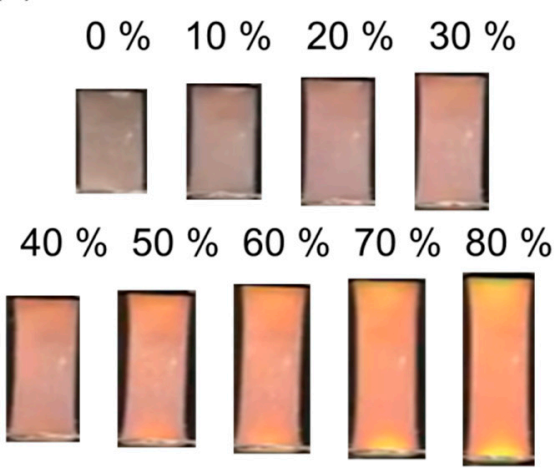

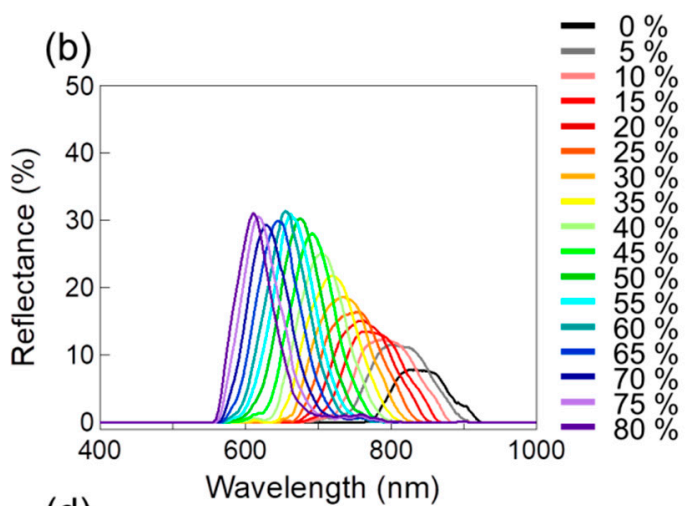

(d)

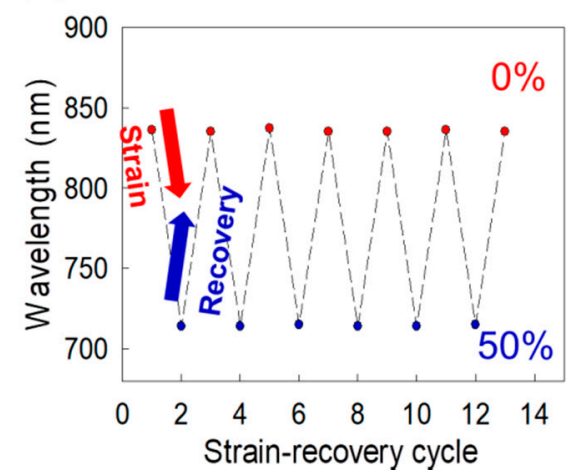

Figure 4. (a) Reflectance spectra of $\mathrm{N}^{*} \mathrm{LC}(x)$ elastomers prepared with different ISBCD concentrations. (b) Reflectance spectra of the $\mathrm{N}^{*}$ LC (2.0) elastomer as a function of applied tensile strain (0-80\%). (c) Photographs of the $\mathrm{N}^{*} \mathrm{LC}(2.0)$ elastomer under applied tensile strains of $0-80 \%$. (d) Mechano-optical stability of the $\mathrm{N}^{*} \mathrm{LC}(2.0)$ elastomer film during compressive/tensile strain cycles from $0 \%$ to $50 \%$.

The shift in the reflection peak wavelength can be explained by the isotropic deformation of typical rubbery materials. Such materials deform isotopically under incompressible conditions, leading to in-plane uniaxial elongation that causes the compression in both the in-plane perpendicular and thickness directions in the same manner. This phenomenon can be expressed by the following equation:

$$
\varepsilon_{\text {theory }}=1-\left(1+\varepsilon_{\mathrm{x}}\right)^{-1 / 2},
$$

where $\varepsilon_{\text {theory }}$ is the theoretical strain in the thickness direction under the applied tensile strain $\varepsilon_{\mathrm{x}}$. In our $\mathrm{N}^{*} \mathrm{LC}$ elastomers, we experimentally evaluated the thickness strain $\varepsilon_{\mathrm{Z}}$ by transforming Equation (1) into $\varepsilon_{\mathrm{z}}=\Delta P / P=\Delta \lambda / \lambda_{0}$, where $\Delta P$ is the change in the helical pitch and $\Delta \lambda$ is the shift of the reflection peak wavelength under the applied tensile strain [52]. As shown in Figure S9, the experimental $\varepsilon_{z}$ values show good agreement with the theoretical $\varepsilon_{\text {theory }}$ values, which indicates that the $\mathrm{N}^{*} \mathrm{LC}(x)$ elastomers undergo isotropic deformation. Thus, an applied tensile strain can be evaluated quantitatively by merely measuring the shift of the reflection peak wavelength. Therefore, our proposed $\mathrm{N}^{*}$ LC $(x)$ elastomers have great potential as mechano-optical sensors with excellent flexibility and stretchability, unlike densely cross-linked LC polymers.

Subsequently, we conducted a tensile test using the $\mathrm{N}^{*} \mathrm{LC}(2.0)$ elastomer. The elastomer exhibited a Young's modulus of $1.02 \mathrm{MPa}$ and a fracture strain of $107 \%$, indicating high stretchability. To further understand the mechano-optical stability, we evaluated the shift of the reflection peak wavelength during compressive/tensile strain cycles. As shown in Figure $4 \mathrm{~d}$, the $\mathrm{N}^{*} \mathrm{LC}(2.0)$ elastomer clearly exhibited the same color change with a slight hysteresis, even after repeated strain and recovery processes. Thus, we conclude that the elastomer maintains high mechano-optical stability during compression and elongation. 


\subsection{Optical Stability in Solvents}

For practical mechano-optical sensors, it is desirable that the optical properties show little dependence on the solvent conditions. When a typical $\mathrm{N}^{*} \mathrm{LC}$ elastomer network is immersed in a solvent, swelling causes network deformation, which drastically affects the optical properties arising from the helically twisted molecular orientation. Although swellable LC polymers have utility as humidity-responsive materials [53,54], this swelling effect interferes with and degrades the resolution of mechano-optical sensing. Therefore, resistance to solvents, especially to common polar solvents such as water and ethanol, is crucial for the broad application of $\mathrm{N}^{*} \mathrm{LC}$ elastomers as mechano-optical sensors. As shown in Figure S10, the $\mathrm{N}^{*} \mathrm{LC}(2.0)$ elastomer exhibited hydrophobicity, as water placed on the elastomer surface formed a droplet and was not absorbed into the elastomer. We also evaluated the environmental stability of the $\mathrm{N}^{*} \mathrm{LC}(2.0)$ elastomer in polar solvents by immersing the elastomer in water or ethanol (Figure 5a). After immersion for 1 week, the $\mathrm{N}^{*} \mathrm{LC}(2.0)$ elastomer showed no color change in either water or ethanol. To further investigate the solvent resistance, the $\mathrm{N}^{*} \mathrm{LC}(2.0)$ elastomer was elongated in water and ethanol environments. As shown in Figure 5b, the $\mathrm{N}^{*} \mathrm{LC}(2.0)$ elastomer exhibited excellent mechano-optical behavior, even in water and ethanol, without any optical degradation. This excellent environmental stability under harsh conditions can be attributed to the wide elastic temperature range and hydrophobicity of the elastomer. These results suggest that our proposed $\mathrm{N}^{*} \mathrm{LC}(x)$ elastomers provide a pathway for realizing mechano-optical sensors or devices that will function in a wide range of extreme environments.

(a)

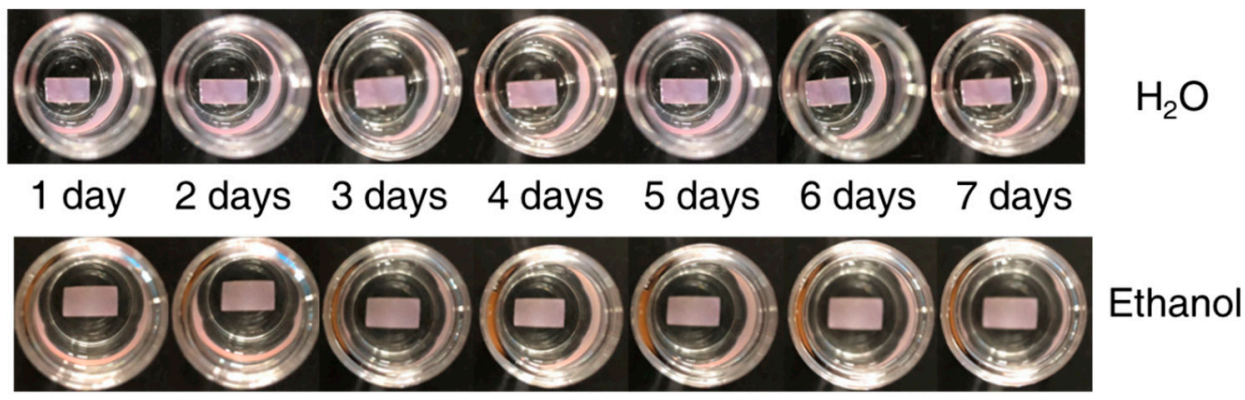

(b)
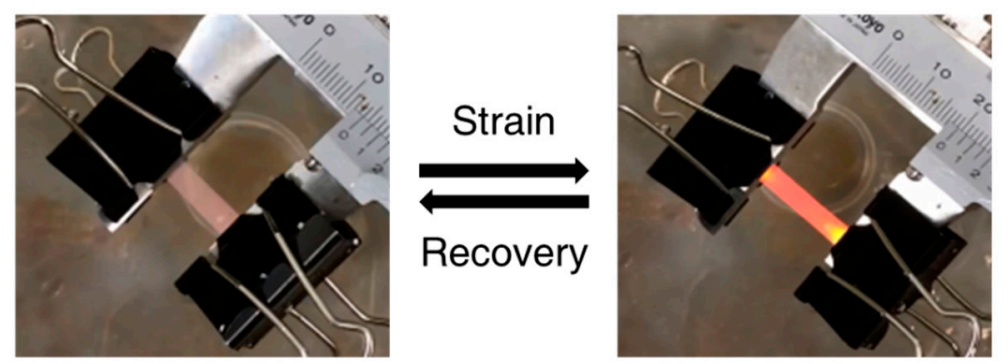

$$
\mathrm{H}_{2} \mathrm{O}
$$
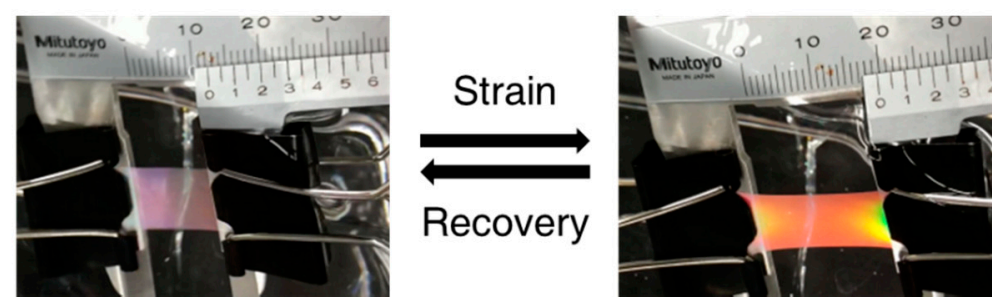

\section{Ethanol}

Figure 5. (a) $\mathrm{N}^{*} \mathrm{LC}$ (2.0) elastomer immersed in water and ethanol over 1 week, and (b) color change under an applied tensile strain in water and ethanol baths. 


\section{Conclusions}

In conclusion, we proposed a design concept for synthesizing thermally, optically, and environmentally stable $\mathrm{N}^{*} \mathrm{LC}$ elastomers by employing cyanobiphenyl units in the elastomer as noncovalent cross-linking sites. Because of their low densities of covalent cross-linking sites, the $\mathrm{N}^{*} \mathrm{LC}(x)$ elastomers exhibited high stretchability and flexibility, which are favorable properties for realizing practical mechano-optical sensors. In addition, the thermal stability of the $\mathrm{N}^{*}$ LC phase could be enhanced by increasing the concentration of cyanobiphenyl units that form noncovalent cross-links in the elastomer. Notably, this noncovalent cross-linking had almost no effect on the mechano-optical response behavior, such as the reflection peak wavelength and mechano-optical stability, but significantly enhanced the environmental stability. The $\mathrm{N}^{*} \mathrm{LC}(x)$ elastomers exhibited excellent mechano-responsive color change properties, with a hypsochromic shift of the reflection peak wavelength under an applied tensile strain and reversible recovery to the original shape and color owing to high elasticity. In addition, the hydrophobicity and large elastic temperature ranges of the $\mathrm{N}^{*} \mathrm{LC}(x)$ elastomers provided excellent resistance to water and ethanol. Based on the excellent physical properties of the $\mathrm{N}^{*} \mathrm{LC}(x)$ elastomers, including high stretchability, reversibility, and stability under harsh conditions, our material design concept of using noncovalent cross-linking sites in $\mathrm{N}^{*} \mathrm{LC}$ elastomers is expected to contribute to various mechano-optical sensor applications in the fields of wearable displays, electric skin, and soft robotics.

Supplementary Materials: The following are available online at https:/ /www.mdpi.com/article/10 .3390/app11115037/s1, Scheme S1: Synthetic route for ISBCD, Text S1: Synthesis of chiral dopant monomer, Text S2: Preparation of PDMS film, Text S3: Cell preparation with rubbing treatment, Text S4: Preparation of $\mathrm{N}^{*} \mathrm{LC}(x)$ elastomers, Figure S1: ${ }^{1} \mathrm{H}-\mathrm{NMR}$ spectrum of ISBCD in $\mathrm{CDCl}_{3}$, Figure S2: ${ }^{13} \mathrm{C}-\mathrm{NMR}$ spectrum of ISBCD in $\mathrm{CDCl}_{3}$, Figure S3: HMQC spectrum of ISBCD in $\mathrm{CDCl}_{3}$, Figure S4: POM image of $\mathrm{N}^{*} \mathrm{LC}$ (2.0) mixtures observed at room temperature before (a) and after (b) polymerization in a rubbing cell, Figure S5: DSC thermogram of 1-LCP (2nd scan, scanning rate of $10^{\circ} \mathrm{C} \min ^{-1}$ ), Figure S6: DSC thermogram of $\mathrm{N}^{*} \mathrm{LC}(2.0)$ elastomer (2nd scan, scanning rate of $10^{\circ} \mathrm{C} \mathrm{min}^{-1}$ ), Figure S7: DSC thermogram of $\mathrm{N}^{*} \mathrm{LC}$ elastomers containing different HAB/CN ratios: (a) 70/10, (b) 60/20, and (c) 50/30 (2nd scan, scanning rate of $10^{\circ} \mathrm{C} \mathrm{min}^{-1}$ ), Figure S8: (a) Color change of $\mathrm{N}^{*} \mathrm{LC}(x)$ elastomers with different chiral dopant concentrations $x(2.0-3.0 \mathrm{~mol} \%)$ under an applied tensile strain of $0 \%$ (left), 40\% (middle), and 80\% (right), and (b) reflection peak wavelengths of $\mathrm{N}^{*} \mathrm{LC}(x)$ elastomers as a function of applied tensile strain $(0-80 \%)$, Figure S9: (a) Schematic illustrations of film deformation by elongation along the $x$-axis (the thickness direction and helical pitch along the $z$-axis, and the in-plane direction along the $y$-axis perpendicular to the elongation direction are compressed as the elongation strain increases) and (b) change in helical pitch $\varepsilon_{\mathrm{Z}}$ (red circles and line) experimentally evaluated using the shift in the reflection peak wavelength and the theoretical thickness strain of rubbery elastomers (black line) under the applied tensile strain $\varepsilon_{Z}$ calculated using a Poisson ratio of 0.5, Figure S10: Photographs of an $\mathrm{N}^{*} \mathrm{LC}(2.0)$ elastomer film: (a) water droplet on the film surface, showing hydrophobicity and (b) contact angle of the droplet on the surface.

Author Contributions: Conceptualization, O.T.; Investigation, K.K., T.S., S.K., K.H., N.A., A.S.; Formal Analysis, K.K., K.H., O.T.; Writing-Original Draft Preparation, K.K., K.H., O.T.; WritingReview and Editing, K.K., K.H., O.T. All authors have read and agreed to the published version of the manuscript.

Funding: This research was supported by JSPS KAKENHI (18H03764 for OT; 19K21131 and 20K15249 for KH), JST A-STEP (JPMJTM19C9), the Ritsumeikan Global-Innovation Research Organization (R-GIRO), and the Cooperative Research Program of the Network Joint Research Centre for Materials and Devices (Tokyo Institute of Technology).

Data Availability Statement: The data that supports the findings of this study are available in the Supplementary Materials of this article.

Acknowledgments: We thank Osaka Organic Chemical Industry for providing the liquid crystal monomers. 
Conflicts of Interest: The authors declare no conflict of interest.

\section{References}

1. Pan, M.; Wang, L.; Dou, S.; Zhao, J.; Xu, H.; Wang, B.; Zhang, L.; Li, X.; Pan, L.; Li, Y. Recent advances in colloidal photonic crystal-based anti-counterfeiting materials. Crystals 2019, 9, 417. [CrossRef]

2. Akamatsu, N.; Hisano, K.; Tatsumi, R.; Aizawa, M.; Barrett, C.J.; Shishido, A. Thermo-, photo-, and mechano-responsive liquid crystal networks enable tunable photonic crystals. Soft Matter 2017, 13, 7486-7491. [CrossRef] [PubMed]

3. Manouras, T.; Vamvakaki, M. Field responsive materials: Photo-, electro-, magnetic- and ultrasound-sensitive polymers. Polym. Chem. 2017, 8, 74-96. [CrossRef]

4. Ishizuki, K.; Aoki, D.; Goseki, R.; Otsuka, H. Multicolor mechanochromic polymer blends that can discriminate between stretching and grinding. ACS Macro Lett. 2018, 7, 556-560. [CrossRef]

5. Wu, P.; Shen, X.; Schäfer, C.G.; Pan, J.; Guo, J.; Wang, C. Mechanochromic and thermochromic shape memory photonic crystal films based on core/shell nanoparticles for smart monitoring. Nanoscale 2019, 11, 20015-20023. [CrossRef]

6. Chao, D.; Yang, Y.; Jia, X.; Berda, E.B. Rationally-designed multi responsive fluorescent switching polymer films. Dyes Pigm. 2019, 167, 77-82. [CrossRef]

7. Liu, H.; Gu, Y.; Dai, Y.; Wang, K.; Zhang, S.; Chen, G.; Zou, B.; Yang, B. Pressure-induced blue-shifted and enhanced emission: A cooperative effect between aggregation-induced emission and energy-transfer suppression. J. Am. Chem. Soc. 2020, 142, 1153-1158. [CrossRef]

8. Stumpel, J.E.; Broer, D.J.; Schenning, A.P.H.J. Stimuli-responsive photonic polymer coatings. Chem. Commun. 2014, 50, 1583915848. [CrossRef] [PubMed]

9. Wintzheimer, S.; Reichstein, J.; Wenderoth, S.; Hasselmann, S.; Oppmann, M.; Seuffert, M.T.; Müller-Buschbaum, K.; Mandel, K. Expanding the horizon of mechanochromic detection by luminescent shear stress sensor supraparticles. Adv. Funct. Mater. 2019, 29, 1901193. [CrossRef]

10. Meng, F.; Du, C.; Zhou, N.; He, X.-Z.; Chen, H. Synthesis and characterization of fluorinated liquid-crystalline elastomers containing chiral liquid-crystalline crosslinking units. Eur. Polym. J. 2013, 49, 3392-3401. [CrossRef]

11. Hu, J.-S.; Liu, X.-F.; Meng, Q.-B.; Zhang, Y. New chiral liquid crystalline monomers, polymers, and elastomers derived from menthol derivatives: Synthesis and mesomorphism. J. Mater. Sci. 2014, 49, 1229-1239. [CrossRef]

12. Bubnov, A.; Domenici, V.; Hamplová, V.; Kašpar, M.; Zalar, B. First liquid single crystal elastomer containing lactic acid derivative as chiral co-monomer: Synthesis and properties. Polymer 2011, 52, 4490-4497. [CrossRef]

13. Varanytsia, A.; Nagai, H.; Urayama, K.; Palffy-Muhoray, P. Accurate control of laser emission from cholesteric liquid crystal elastomers. Mol. Cryst. Liq. Cryst. 2017, 647, 216-222. [CrossRef]

14. Shang, Y.; Wang, J.; Ikeda, T.; Jiang, L. Bio-inspired liquid crystal actuator materials. J. Mater. Chem. C 2019, 7, 3413-3428. [CrossRef]

15. Kragt, A.J.J.; Zuurbier, N.C.M.; Broer, D.J.; Schenning, A.P.H.J. Temperature-responsive, multicolor-changing photonic polymers ACS Appl. Mater. Interfaces 2019, 11, 28172-28179. [CrossRef]

16. Zheng, Z.; Liu, B.; Zhou, L.; Wang, W.; Hu, W.; Shen, D. Wide tunable lasing in photoresponsive chiral liquid crystal emulsion. J. Mater. Chem. C 2015, 3, 2462-2470. [CrossRef]

17. Mulder, D.J.; Schenning, A.P.H.J.; Bastiaansen, C.W.M. Chiral-nematic liquid crystals as one dimensional photonic materials in optical sensors. J. Mater. Chem. C 2014, 2, 6695-6705. [CrossRef]

18. Zhai, F.; Feng, Y.; Zhou, K.; Wang, L.; Zheng, Z.; Feng, W. Graphene-based chiral liquid crystal materials for optical applications. J. Mater. Chem. C 2019, 7, 2146-2171. [CrossRef]

19. Jiang, Y.; Cong, Y.; Zhang, B. Novel cholesteric liquid crystalline elastomers containing dimer type nematic and chiral liquid crystalline side-chains. RSC Adv. 2016, 6, 81902-81912. [CrossRef]

20. Jiang, Y.; Cong, Y.; Zhang, B. Synthesis and characterization of chiral smectic side-chain liquid crystalline elastomers containing nematic and chiral mesogens. New J. Chem. 2016, 40, 9352-9360. [CrossRef]

21. Meng, F.; Bai, L.; Ma, S.; Lan, X.; Li, X.; Wang, Z. Cyclosiloxane-based liquid-crystalline elastomers containing fluorinated mesogens and chiral crosslinking groups. Colloid Polym. Sci. 2014, 292, 1511-1519. [CrossRef]

22. Varanytsia, A.; Nagai, H.; Urayama, K.; Palffy-Muhoray, P. Tunable lasing in cholesteric liquid crystal elastomers with accurate measurements of strain. Sci. Rep. 2015, 5, 17739. [CrossRef]

23. Cao, Y.; Hamad, W.Y.; MacLachlan, M.J. Broadband circular polarizing film based on chiral nematic liquid crystals. Adv. Opt. Mater. 2018, 6, 1800412. [CrossRef]

24. Chen, R.; Lee, Y.-H.; Zhan, T.; Yin, K.; An, Z.; Wu, S.-T. Multistimuli-responsive self-organized liquid crystal Bragg gratings. Adv. Opt. Mater. 2019, 7, 1900101. [CrossRef]

25. Lee, K.M.; Rumi, M.; Mills, M.S.; Reshetnyak, V.; Evans, D.R.; Bunning, T.J.; McConney, M.E. A different perspective on cholesteric liquid crystals reveals unique color and polarization changes. ACS Appl. Mater. Interfaces 2020, 12, 37400-37408. [CrossRef] [PubMed]

26. Ma, L.-L.; Hu, W.; Zheng, Z.-G.; Wu, S.-B.; Chen, P.; Li, Q.; Lu, Y.-Q. Light-activated liquid crystalline hierarchical architecture toward photonics. Adv. Opt. Mater. 2019, 7, 1900393. [CrossRef] 
27. Guo, J.; Wu, H.; Chen, F.; Zhang, L.; He, W.; Yang, H.; Wei, J. Fabrication of multi-pitched photonic structure in cholesteric liquid crystals based on a polymer template with helical structure. J. Mater. Chem. 2010, 20, 4094-4102. [CrossRef]

28. Wu, X.; Yu, L.; Cao, H.; Guo, R.; Li, K.; Cheng, Z.; Wang, F.; Yang, Z.; Yang, H. Wide-band reflective films produced by side-chain cholesteric liquid-crystalline elastomers derived from a binaphthalene crosslinking agent. Polymer 2011, 52, 5836-5845. [CrossRef]

29. Finkelmann, H.; Kim, S.T.; Muñoz, A.; Palffy-Muhoray, P.; Taheri, B. Tunable mirrorless lasing in cholesteric liquid crystalline elastomers. Adv. Mater. 2001, 13, 1069-1072. [CrossRef]

30. Lagerwall, J.P.F.; Schütz, C.; Salajkova, M.; Noh, J.H.; Park, J.H.; Scalia, G.; Bergström, L. Cellulose nanocrystal-based materials: From liquid crystal self-assembly and glass formation to multifunctional thin films. NPG Asia Mater. 2014, 6, e80. [CrossRef]

31. Nagai, H.; Urayama, K. Thermal response of cholesteric liquid crystal elastomers. Phys. Rev. E 2015, 92, 022501. [CrossRef]

32. Ranjkesh, A.; Yoon, T.-H. Thermal and electrical wavelength tuning of Bragg reflection with ultraviolet light absorbers in polymer-stabilized cholesteric liquid crystals. J. Mater. Chem. C 2018, 6, 12377-12385. [CrossRef]

33. Fuchigami, Y.; Takigawa, T.; Urayama, K. Electrical actuation of cholesteric liquid crystal gels. ACS Macro Lett. 2014, 3, 813-818. [CrossRef]

34. Saha, A.; Tanaka, Y.; Han, Y.; Bastiaansen, C.M.W.; Broer, D.J.; Sijbesma, R.P. Irreversible visual sensing of humidity using a cholesteric liquid crystal. Chem. Commun. 2012, 48, 4579-4581. [CrossRef] [PubMed]

35. Hu, J.-S.; Zhang, B.-Y.; Jia, Y.-G.; Chen, S. Side-chain cholesteric liquid crystalline elastomers derived from a mesogenic crosslinking agent. Macromolecules 2003, 36, 9060-9066. [CrossRef]

36. Carfagna, C.; Amendola, E.; Giamberini, M. Liquid crystalline epoxy based thermosetting polymers. Prog. Polym. Sci. 1997, 22, 1607-1647. [CrossRef]

37. Han, M.; Guo, K.; Wang, F.; Zhu, Y.; Qi, H. Synthesis, characterization, and properties of thermosets based on the cocuring of an acetylene-terminated liquid-crystal and silicon-containing arylacetylene oligomer. J. Appl. Polym. Sci. 2017, 134, 45141. [CrossRef]

38. Dingemans, T.J.; Iqbal, M. Liquid crystal thermoset resins for high temperature composites and adhesives. Plast. Rubber Compos. 2010, 39, 189-194. [CrossRef]

39. Brömmel, F.; Kramer, D.; Finkelmann, H. Preparation of liquid crystalline elastomers. In Liquid Crystal Elastomers: Materials and Applications, 1st ed.; de Jeu, W.H., Ed.; Springer: Berlin, Germany, 2012; Volume 250, pp. 1-48. [CrossRef]

40. Sánchez-Ferrer, A.; Torras, N.; Esteve, J. Integration of liquid-crystalline elastomers in MEMS/MOEMS. In Liquid Crystalline Polymers, 1st ed.; Thakur, V.K., Kessler, M.R., Eds.; Springer: Cham, Switzerland, 2016; Volume 1, pp. 553-582. [CrossRef]

41. Kato, T.; Uchida, J.; Ichikawa, T.; Soberats, B. Functional liquid-crystalline polymers and supramolecular liquid crystals. Polym. J. 2018, 50, 149-166. [CrossRef]

42. Yoshizawa, A. Liquid crystal supermolecules stabilizing an optically isotropic phase with frustrated molecular organization. Polym. J. 2012, 44, 490-502. [CrossRef]

43. Wei, Z.; Wang, L.; Li, J.; Liu, X.; Jiang, S. Cyanobiphenyl-mesogened liquid crystalline polymer bonded on silica as the stationary phase with shape and polarity recognition for LC. Chromatographia 2011, 73, 5-16. [CrossRef]

44. Dwivedi, K.K.; Dwivedi, M.K.; Tiwari, S.N. Study of intermolecular interactions in liquid crystals: para-Butyl-p'-cyano-biphenyl. J. Cryst. Process Technol. 2014, 4, 31-38. [CrossRef]

45. Zhao, J.; Yuan, Y.; Chen, L.; Li, Y.; Zhang, H. High performance liquid crystalline physical gels prepared by side chain liquid crystalline polymers. Polymer 2018, 151, 75-83. [CrossRef]

46. Shin, S.; Park, M.; Cho, J.K.; Char, J.; Gong, M.; Jeong, K.-U. Tuning helical twisting power of isosorbide-based chiral dopants by chemical modifications. Mol. Cryst. Liq. Cryst. 2011, 534, 19-31. [CrossRef]

47. Ku, K.; Kimura, S.; Yuasa, K.; Hisano, K.; Tsutsumi, O. Control of molecular-level mechano-optical response of chiral liquidcrystalline elastomers. In Proceedings of the SPIE 11477, Molecular and Nano Machines III, San Diego, CA, USA, 25 August 2020; p. 1147703. [CrossRef]

48. Kelly, S.M. Anisotropic networks, elastomers and gels. Liq. Cryst. Today 1996, 6, 1-6. [CrossRef]

49. Hu, J.-S.; Zhang, B.-Y.; Zheng, Y.-Y.; Li, Q.-Y. Synthesis and phase behavior of side-chain cholesteric liquid-crystalline elastomers derived from a chiral crosslinking agent. React. Funct. Polym. 2005, 64, 1-11. [CrossRef]

50. Belmonte, A.; Ussembayev, Y.Y.; Bus, T.; Nys, I.; Neyts, K.; Schenning, A.P.H.J. Dual light and temperature responsive micrometersized structural color actuators. Small 2020, 16, 1905219. [CrossRef]

51. Ogiwara, A.; Kakiuchida, H. Thermally tunable light filter composed of cholesteric liquid crystals with different temperature dependence. Sol. Energy Mater. Sol. Cells 2016, 157, 250-258. [CrossRef]

52. Xie, P.; Zhang, R. Liquid crystal elastomers, networks and gels: Advanced smart materials. J. Mater. Chem. 2005, 15, 2529-2550. [CrossRef]

53. Dai, M.; Picot, O.T.; Verjans, J.M.N.; de Haan, L.T.; Schenning, A.P.H.J.; Peijs, T.; Bastiaansen, C.W.M. Humidity-responsive bilayer actuators based on a liquid-crystalline polymer network. ACS Appl. Mater. Interfaces 2013, 5, 4945-4950. [CrossRef]

54. Haan, L.T.d.; Verjans, J.M.N.; Broer, D.J.; Bastiaansen, C.W.M.; Schenning, A.P.H.J. Humidity-responsive liquid crystalline polymer actuators with an asymmetry in the molecular trigger that bend, fold, and curl. J. Am. Chem. Soc. 2014, 136, 10585-10588. [CrossRef] 